\title{
GAFA speaks: Metaphors in the promotion of cloud technology
}

\begin{abstract}
Purpose: The article explores persuasive rhetoric in the legitimization of cloud computing by critically scrutinizing metaphorical devices utilized by leaders of the cloud industry. This article introduces a critical approach to the promotion of cloud technology.

Design/methodology/approach: 13 video clips from YouTube.com were analysed, containing presentations and talks delivered by leaders of Google, Apple, Facebook and Amazon - four of the most influential companies within the IT industry, sometimes referred to as GAFA. With the help of conceptual metaphor theory, often-repeated metaphors for cloud technologies reveal what properties were promoted and hidden.

Findings: GAFA mainly used the same persuasive metaphors to promote cloud computing's positive aspects. Potentially negative or complex issues were mostly avoided. Implicitly, GAFA exerts power through the extensive dissemination of their metaphors and these are used in order to negotiate and overcome doubts about cloud computing and related technologies.
\end{abstract}

Originality/value: This is the first study aimed at understanding the persuasive rhetoric of GAFA, seen as a uniform object of study, in the legitimization of cloud computing.

Keywords: cloud providers, cloud technology, Conceptual metaphor theory, marketing rhetoric, GAFA

\section{Introduction}

In the last decade digital technologies have expanded to encompass cloud technology, i.e. remote archiving and processing. This new technology is not yet domesticated or commonly taken for granted, nor has it been fully accepted or exploited to its full potential. Although a successive implementation of cloud technology is occurring, both in the public sector and the private sphere, cloud providers are pushing continually for extension of both pace and scope. Arguably, the broad ranging revelations by Edward Snowden in 2013 served as a major setback for the cloud industry. Awareness and suspicion relating to the privacy and security of remote storing and processing heightened and was hotly debated on a global scale. It is therefore of great concern to learn more about how cloud technology is promulgated. The aim of this article is to critically scrutinize metaphorical devices utilized by leaders of the cloud industry as they argue for the extension of the pace and scope of cloud technology implementation.

The article examines the most influential cloud providers - represented by Google, Amazon, Facebook and Apple, sometimes referred to as GAFA in critical discussions- by scrutinizing their visions of an evolving cloud-based society. GAFA has been described as "dominating the ecosystem of connective media" (van Dijck, 2013, p. 163), which also is a good reason for exploring this chosen group. The study will uncover GAFA's visions of cloud technology by studying how it is propelled through marketing rhetoric. 
The current study is underpinned by four assumptions. First, GAFA has a fundamental interest in pushing visions of a future characterized by the strengthened presence of and dependence on cloud technology. Second, to generate impact, these visions need to be disseminated in the most popular media globally available, YouTube, which has therefore been targeted for the empirical data collection. Third, since technological visions are difficult to communicate to non-technological professionals, metaphors are used liberally. Indeed, building on the theoretical viewpoint of Lakoff and Johnson (2003), metaphors are used to make abstract phenomena more concrete. Fourth, metaphors of technology rich futures, put forward by corporations with a vested interest, should primarily be understood as vehicles of persuasion. As such, metaphors in the current context are used to fixate understandings of future societal outcomes. From a social science perspective, this represents the fallacy of technological determinism.

If the metaphors of GAFA portray non-negotiable socio-technical trajectories, it is also implied that technological development forces societal change. Technological determinism has been thoroughly criticized by socio-technological research within Science and Technology Studies (STS), where information technology (IT) is seen as both a technological and a social construct, integral to organisations (e.g. Sturken et al., 2004). Furthermore, the study makes use of a typology of metaphor categories, developed by Dahlbom and Janlert (1988). The research questions are:

- Which metaphorical variations are visible in the empirical material?

- How can we understand GAFA's visions through their metaphors?

In the following, the focus is the multi-layered technology of cloud computing. Thereafter, theoretical and methodological aspects of studying metaphors in texts that promote new IT are presented, as well as earlier research on IT metaphors. The main part of the article is an in-depth discussion of the metaphors found in the material.

\section{Cloud computing as an evolving technology}

Barnatt (2010) identified cloud computing's four key features as task-centric, dynamically scalable, device-independent and with no fixed price. Furthermore, cloud computing is characterized by internet-based delivery of software, platform and infrastructure services.

The broad acceptance of this new technology is a curious and interesting social phenomenon, since organisations usually resist change (Marshall, 2010). The overt promise of cloud technology as transformative is seductive. Organisations worldwide increasingly invest due to competition, innovation, globalization, etc. Claims are raised of great economic advantage and far-reaching change. Organisations may change, due to modifications in collaboration with stakeholders, through blurring boundaries, even between work and leisure. Furthermore, internal processes, work tasks and workforce may change (Willcocks et al., 2014). Additionally, cloud technology is often the precondition for the development of other 
evolving digital technologies, such as the "internet of things" (e.g. Hwang et al., 2013; Wang et al., 2011) “cloud manufacturing” (e.g. Xu, 2012), "heterogeneous computing” (e.g. Buyya et al., 2009) and "big data” (e.g. Agrawal et al., 2011).

Substantial shares of organisations' economical resources are continually placed in IT and it is therefore critical to understand reasons for failure (e.g. Bartis and Mitev, 2008). Furthermore, the changing business model of IT, from product to service, is crucial in the shift to cloud (Carr, 2008). This change in the understanding of IT is often stressed - e.g. "users do not buy technology but a capability" (Willcocks et al., 2014, p. 26). Nonetheless, IT is often mistakenly understood as neutral. However, social constructivist research focuses on the reciprocity between IT and organisations i.e. how such technology is both affected by and affects how work is executed.

Social constructivist research examines socio-technical complexities concerning new technology and organisations (e.g. Kling, 1996; Orlikowski, 1992). Sturken et al. (2004) discuss the lack of informed discussions on the impact of new technology in organisations. Others indicate the interpretative flexibility of technology, since it "can and do[es] vary by different users, by different contexts of use, and by the same users over time" (Orlikowski, 1992, p. 403). Furthermore, Kling (1996) emphasizes the importance of comprehending organisations' work tasks when studying how IT systems are understood and used. Research within computerization frequently draws "implicit assumptions about the way organizations behave” (p. 114). Clearly, there is a need to understand cloud computing's properties in organisations. Since metaphors are constitutive, cloud vendors' use of metaphors can help us to explore cloud technology's properties in organisations. In order to investigate the use of metaphors relating to cloud technology, conceptual metaphor theory, suggested by Lakoff and Johnson (2003) will be utilized.

\section{Metaphors and IT}

Lakoff and Johnson (2003) argue that metaphors are intrinsic - we live by them. Therefore, metaphors can be seen as essential in understanding the world, "that we understand one concept in terms of another" (p. 113). Human experiences are usually so rich that we struggle to make sense of them on their own terms. We must make reference to other kinds of entities and experiences in order to explain them.

Every metaphor can be explained as structured by two conceptual domains: a target domain and a source domain (Lakoff 1993, p. 206). The target domain frequently contains abstract notions that are difficult to communicate purely with the help of more concrete concepts in the same domain. For instance, the fairly abstract notion of cloud technology could be explained through more concrete concepts within its own domain, with terms such as computers, screens, devices and machines. However, there are limits to the resources available in the same domain. Metaphors are therefore understood as concepts taken from another (source) domain. Various source domains involve separate clusters of concepts that can be appropriated in order to achieve richer communication about the entities in the target domain. In the example argument is war, argument represents the target domain and war 
represents the source domain. Furthermore, Lakoff (1993) explains that metaphors are mappings across these conceptual domains and represent ontologies that are fixed within these domains. Lakoff (1993) describes this with the metaphor of love is a journey, in which journey is taken from the source domain and love is that which is to be clarified: the target domain. There are several expressions that involve talk about love as a journey, for instance; we've reached a dead-end, we're at a cross-road, we're stuck, the wheels are spinning, which thus represent ontological mappings from one domain to another.

Vague concepts or phenomena are often described "in terms of more concrete concepts, which are more clearly delineated in our experience” (p. 113). New IT can be experienced as both concrete and vague, resulting therefore in a variety of metaphors, which describe different properties. Lakoff and Johnson (2003) understand metaphors as dynamic and "openended", and defined in terms of "interactional properties", rather than inherent. Accordingly, people tend to use several metaphors to comprehend and communicate the meanings of a single activity, concept or artefact. Each metaphor can communicate a separate aspect while minimizing, or indeed making invisible, others. Different metaphors are therefore inherently conflicting, depending on the properties emphasized. Consequently, people operate with a system of metaphors whose parts often fail to be consistent.

Metaphors are not only used to make sense; they can also function as constitutive. While Lakoff and Johnson are concerned with metaphors as devices for navigating everyday life, the focus here is on metaphorical visions. Frequently, as we shall see, such visions involve attempts at painting a picture of what it could be like to navigate everyday life in the future with the aid of technological devices. Thus, metaphors are far from innocent; they can be used for certain reasons and can therefore be perceived as political, executing power by their users (Lakoff \& Johnson, 2003).

For our purposes, we emphasise that metaphors are used as persuasive devices (e.g. Johansson, 1997). Furthermore, every metaphorical choice highlights certain aspects and downplays others. It can be expected that metaphors will be chosen to highlight properties of power, change, control, creativity, efficiency, competitiveness etc. Johansson (1997) argues that language links to models of thought in the process of persuasion - also regarding the introduction of a new technology, i.e. it is "a language game, a rhetorical process, in which various actors with various kinds of interest in a certain artefact or technology try to influence how it is designed, how it is implemented and, later, how it is used” (p. 11).

Following Lakoff and Johnson (2003) we can expect metaphors of IT to be wide-ranging and frequently in conflict with each other. On the one hand, IT can be understood through the metaphor of magic (Lynn Kaarst-Brown and Robey, 1999). On the other hand, IT is often viewed as unexciting; it should "just work". Some argue the best technology is "simple", “frictionless" (e.g. Carr, 2014, p. 180ff), “invisible” (e.g. Norman, 1998) or "neutral” (e.g. Hamilton, 2000). Technology is thus viewed as a "neutral tool”, steered and manoeuvred by the user. The tool metaphor builds on the image of technology as an aid (Johansson, 1997, pp. 22). 
Another "neutral tool" metaphor, consistently used since the late 50s, is the "utility" metaphor, i.e. IT or computers are compared with utilities such as water and electricity (Lindh, 2016). Yet another metaphor, representing the neutrality of a tool, is IT as a "solution" to a specific problem "able to be 'applied' to the relevant issue" (Hamilton, 2000, p. 249). A similar metaphor of technological neutrality is "calm technology" (e.g. Case, 2015).

In opposition to "calm technology", the agency of technology is depicted in the concept "revolution”. "Revolution" holds the promise, or threat, of radical change. Since the early days of the computer it has been denoted as "revolutionary" - which is also the case with cloud computing (e.g. Carr, 2008). Winner (1986) noted that the "revolution" rhetoric, associated with computers, seemed to invite comparison with political revolutions, i.e. the transformation of society. A contrasting metaphor is "hype", which seems to suggest that there is an abundance of talk of revolutionary transformation, but very little will happen. Not surprisingly, cloud computing is also being subjected to hype-acquisitions (Buyya et al., 2009).

Yet another metaphor, that puts technological agency before human agency, is “automation”. According to Johansson (1997), "[t]he automaton metaphor builds on the rational, bureaucratic and industrial system view developed in the 1950s and -60s” (p. 22). In line, Hirschheim and Newman (1991) state that "automation" negates human agency and is enslaving. According to Johansson (1997), other words used to describe computer automation are "second self”, “substitute”, “max smart” and “intellectual” (p. 22). Carr (2014) also pictures automation in the following way: "All too often, automation frees us from that which makes us feel free. The point is not that automation is bad [...] Deployed wisely, automation can relieve of us drudge work and spur us on to more challenging and fulfilling endeavours" (p. 17). He is still worried about the consequences of automation, such as the "erosion of effort and engagement, or a waning of agency and autonomy, or a subtle deterioration of skill” (p. 18).

Furthermore, IT is often described in anthropomorphic terms, such as "brains”, "memory” or "intelligence" (e.g. Hamilton, 2000). Johansson (1997) notes that computers' role in augmenting mental abilities creates a strong link to intelligence-centred metaphors such as “electronic brains” and "artificial intelligence”. Olson et al. (2015) have identified concepts in academic articles (1900-2013) used to describe the vision of a future social-digital world: "semantic web”, “ubiquitous computing/web”, "pervasive computing”, "internet of things”, “digital living”, “real world internet”, “ambient intelligence”, "smart environment”, "semantic web” and "system of systems”.

Often, the same metaphors are used repeatedly whenever a new technology is pushed by industry. Some of the metaphors used for IT can also be identified in connection to other types of services, products or even politics (e.g. Winner, 1986, p. 99). 
In sum, building on Lakoff and Johnson (2003) all these different metaphors are complementary, where each one makes certain perspectives visible while hiding others. While we tend to understand technology as concrete and solid entities, their functioning and usage are frequently quite abstract. In the understanding of technology-in-the-making, we often lack an existing vocabulary to fall back on. This opens up for a system of metaphors, where several conceptual resources may be taken from the same or from different source domains (Lakoff 1993, p. 241). From the source domains, we usually explore resources that are simple, common, concrete and prototypical and can be parts of the body, animals, plants, weather, containers, up/down etc. In the examples above, human brain, tool, life, world, change etc. can be identified as source domains.

\section{GAFA cloud metaphors}

The empirical material consists of 13 video clips available on YouTube.com, containing presentations and talks at events, delivered by leaders of Google (G), Apple (Ap), Facebook (F) and Amazon (AM). The search terms were "Google"/”Apple"/"Facebook"/”Amazon”, "2015", "summit" and "event”. Furthermore, "snowballing” was used in the searches by looking at other clips suggested. The video clips were limited to presentations from 2015 in order to collect as recent material as possible. The video clips (table 1) were analysed during the period December 2015-March 2016.

Table 1. Record of 13 analysed video clips from GAFA, published in 2015 (14 posts due to one event covering both Google and Facebook, World Economic Forum, Davos).

The video clips' content was analysed in a qualitative content analysis. Detailed notations were made when watching the videos with attention to when technology was talked about with concepts different to those clearly identified to the target domain of cloud computing, i.e. PC, information technology, Internet etc. This enabled the identification of several useful source domains such as change, modality and life (all emphasized in Lakoff 1993). The units of analysis contained metaphors - i.e. descriptions of cloud technologies - that were frequently repeated both within the same video and reoccurring across several presentations. In the next stage, notations were reviewed and the most frequently occurring metaphors were identified. Thereafter, metaphors were clustered according to separate source domains, utilizing the three broad categories of conceptual metaphors by Lakoff and Johnson (2003):

- Structural

- Ontological

- Orientational, or spatial

Structural metaphors bring the structure of entities into play. Here, "one concept is metaphorically structured in another" (p. 15). To give an example, time can be described in financial terms: "time is money". This metaphor can build on several common features. Time can be spent and lost, time is limited - all such features suffice in talk about money. Ontological metaphors are associated with the view of the world and the self. They are descriptive and make intangible objects and phenomenon tangible. They supply a sense of boundary and substance to things or bounded spaces, i.e. social relations are described as "networks", “accessibility" and "sharing”. Orientational metaphors describe spatial 
orientation. They highlight basic physical experiences like "up” or “down”, "in” or "out” etc. Example of spatial metaphors could be words like more or good, control, big - all with connotations to something that is up. "High speed" is connected to orientational metaphors with the description "high". Lakoff and Johnson (2003) emphasize the cultural coherence, since the same words have different meanings in different cultures. Accordingly, in our society to have control is important and therefore "up". The same goes for modality metaphors like "easy" and "simple", which were found in the GAFA rhetoric, presented below. Such words are used to specify the advantages of cloud services and are thus resources taken from the source domain "up". In contrast, the metaphors of "difficult” and "hard” would be in the source domain of "down” (cf. Lakoff \& Johnson, 2003, p. 19-20).

Since Lakoff and Johnson's (2003) conceptual metaphor theory only helps to identify metaphors in GAFA rhetoric, we saw a need to categorize the metaphors in relation to the target domain, i.e. concepts native to cloud computing and related technologies. The analysis of the identified metaphors is therefore based on a division of computing metaphors into three categories - structural, functional and system - created by Dahlbom and Janlert (1988). Each category is further explained under the headings below. Overlaps between different categories have been unavoidable as all metaphors involve simplification and the collapse of more complex communication.

\section{Structural metaphors}

Structural metaphors are used to emphasize computers or computer systems' mode of operation - like clockwork or a computer system as a community - or the process of building computer systems - like programming (Dahlbom and Janlert, 1988). The metaphors answer the question: How are computers or computer systems constructed and how do they operate? In the rhetoric of GAFA, five structural metaphors were used extensively:

Cloud technologies as

- Revolutionary

- World

- Ecosystem

- Network

- Life

These metaphors have inclusiveness in common. A revolution is intrinsic; a world comprises everything; an ecosystem includes a complete system of integral parts; a network connects different things/humans; life is everything we are part of.

\section{Revolutionary metaphor}

Structural metaphors are often concerned with a shift from one structure to another. The most dramatic articulations draw on revolutionary metaphors. Obviously, such metaphors signal a break with previous conducts, moving into another reality. The revolutionary metaphor has been overexploited in marketing for decades, in a variety of industries. Audiences have been 
accustomed to everything from toothbrushes to detergents being revolutionary. Nonetheless, it is a concept that is frequently used in the material. Some examples are:

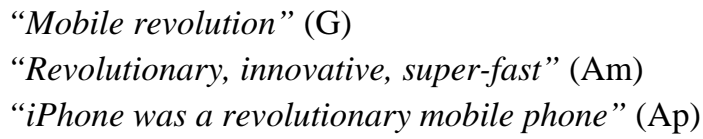

The above examples are characterized by a routinized usage of the concept. However, when building a more sophisticated argument about a shift from one structure to another, there are often other kinds of metaphors used. The favoured instrument for such an approach is "transformative" or "disruptive":

Cloud computing is the biggest technology shift in our lifetime... it's so disruptive to their existing businesses... but it's really hard to fight gravity... an unbelievable opportunity to completely reinvent... businesses, add new customer experiences, and do so much faster than ever before. (Am)

Here, the revolution is characterized as disruptive and inevitable. However, it can also be characterized as empowering. Amazon claims that "we're gonna change the world” adding that customers can look forward to a "fun, interesting, educational and transformational journey”. Amazon also talks about "using the cloud to accelerate digital transformation”. While Amazon is concerned with what happens in the cloud, Apple, more focused on mobile devices, praises their "truly transformative apps" and claims that their products "redefine and transform the way people work in the enterprise". Here as well, the transformative nature of their mobile technologies is a source of pride:

The iPhone continues to change so many things in our lives and we're incredibly confident that research is going to transform medical research in a way that's truly profound and we're so proud to be a part of it. (Ap)

Furthermore, Apple talks about iPads as transformative and services as "forever changing how we pay for things". Likewise, Apple Music "will change how you experience music forever". Apple have also "changed so many parts of all of our lives and transformed the world in the process”. It seems that users should trust Apple's developers as they transform life as we know it.

\section{World metaphor}

The revolutionary talk also extends into the world metaphor. Apple states: "We want to talk about the next opportunity to change the world". Several persuasive statements are concerned about moving to another "world". This implies switching to another type of reality altogether. Amazon states, you have to move "from the old world to this cloud world". Facebook promotes their different applications as "a world of tools" and Google as "a multi-screen world”. In such cases, technology seems to constitute a world of its own. There is a certain fluidity to the associations linked to the world metaphor. There is talk of another world, consisting purely of technology, but also of users being able to step in to this other reality. Used in this way, the metaphor connects to seductive images of fiction (literature, film, 
games) in which it becomes possible to escape the routines of everyday life, entering into magical and alternative worlds.

\section{Ecosystem metaphor}

"Ecosystem" is a metaphor widely used in the IT sector. In the marketing rhetoric of GAFA the term is used in different contexts. For instance, Google refers to specific applications, such as "Google Play ecosystem"; Amazon has "broad partner ecosystem of Independent Software Vendors", or "robust partner ecosystem", or a combination of partners and products: "We [Google] build the hardware along with our ecosystem partners so that they can guide the ecosystem forward”. Common for all of these is the appropriation of a concept originally used to describe the natural world for descriptions of interlinked bundles of technology. Users are therefore subtly nudged away from images of technology as artificial, hard and invasive. They are pushed into an understanding of technology as natural, coherent, soft and organic.

The ecosystem metaphor can communicate different relationships compared to the "world". While users can move into a world, the ecosystem surrounds them. For instance, Apple states that: "For artists we've built an ecosystem [...] one place, one complete thought around music".

Naturally, all computer scientists have been educated with the concept "system" as a core notion. It is therefore difficult to understand the addition of the prefix "eco" as anything other than a rhetorical resource.

\section{Network metaphor}

The network metaphor describes situations where everything is connected. This metaphor can be used to describe an urgent transformation of society. To be networked appears as obligatory and not being networked is problematic. For instance, Facebook states: "we need to connect all those on the internet who aren't yet connected" (F). As this statement refers to people active on internet, and therefore implicitly networking, the metaphor hides the extended appeal "not yet connected through Facebook". Much rhetoric is aimed at promoting contact between friends and families, i.e. people who tend to be already interacting off-line. When Facebook says, "we need", it is, on the face of it, an altruistic statement from a corporation wanting to make the world a better place. Nonetheless, below this altruistic finish, there is a wish to connect everyone through the platform of Facebook. Therefore, it involves substantial aspirations of centralised power, strengthening its position as an obligatory passage point (Callon, 1986). A network where participants are connected is complex, but if everything runs through Facebook, technology can be developed in order to process, structure and manage communication for everyone.

As the leader of social networking platforms, counting more than 1.5 billion users, Facebook holds tremendous power over global communication. However, they are seemingly far from satisfied, granted they reach the members of the network, but not those outside. This can be talked about as a problem through the usually positive metaphor of "inclusion". Therefore, judging by the material, Facebook wants to create a better world, include everyone, and view 
only technical issues as hindrances, such as the very physical accessibility to the network. This goal of including everyone in cloud technology is also voiced by Google: "technology can serve people all over the world". Google wants to "leave no one behind", while Amazon claims that companies can "move quickly or be left behind", therefore "cloud is not that much of a choice". Facebook states that "we need to get the whole world on the internet", while musing on: "imagine what we can do if we get to... hopefully everyone".

\section{Life metaphors}

The most surprising finding among the structural metaphors was the heavy emphasis on life. Three variations of life-metaphors were found in the material, i.e. technology as life management, life changing and true presence. Google, Facebook and Apple are all intent on promoting technology that assists people in the management of their lives. Google most pointedly argues this:

The Smart phone, powerful and familiar, is increasingly at the center of how we manage our lives, including accessing TV shows, movies, music, games and more....the phone becomes your best remote $(\mathrm{G})$

From this perspective, life is something to be managed through technological devices, even by remote control. Implicitly, this suggests a collapse between notions of a divide between online and off-line behaviour. This suggestive image of life mediated through technology can be expressed in various ways. Facebook wants to "help people in their daily lives", while Google states that "we're making life easier than ever to move between screens here in life, whether it's the phone in your pocket or the TV in your living room”. Apple talks, instead, of devices such as Apple Watch, serving to optimize everyday existence, i.e. "helping our users live a better day". The idea, that technology can optimize life and be a solution to everyday problems, seems to occupy GAFA. If users are no longer occupied with trying to accomplish trivial, mundane activities, life would be transformed and their brains could be used for other, more important or fun, things. Therefore, cloud technology can be seen as both optimizing and transforming life. What the metaphor hides, is the notion of the automation of life. Automation can, of course, in some sense be liberating, but may also prohibit spontaneous experiences in life. In his discussion on automation, Carr (2015) uses the metaphor of a "glass cage” surrounding humans while machines increasingly manage our lives for us.

Life metaphors are closely related to notions of revolution. Google puts it bluntly as "technology is life changing" and that it is making "a difference to a fundamental part of peoples' lives". Apple is similarly direct when describing their technology as "life-changing", a metaphor Apple frequently uses. At one point it is connected to the confession that "we have always wanted to make the biggest difference we could make”. The implication of such statements is that the ambition is not really to optimize technological tools, but rather to be a vehicle for social engineering. In this way, GAFA flies under the radar for what can only be described as political projects, changing the way people communicate and relate to each other. This is often put forward quite straightforwardly while simultaneously ignoring the complexities of what it means to "make life better". Instead, technology is suggested as the only solution: 
"We will succeed... to find ways for technology to make everyone's lives better" (F)

"To make the best products in the world that empower people, that enrich their lives" (Ap)

Sometimes, speakers move deeper into the issue of how life is made better, with the notion of making life "more immersive" with "deep interactive experiences". This can be done through the existence of VR technology and artificial intelligence. This is most clearly emphasized by Google’s Eric Schmidt:

The internet will disappear. There will be so many IP addresses because of IPV6, so many devices, sensors, things that you're wearing, things that you interacting with that you won't even sense it'll be part of your presence all the time. Imaging you walk into a room and the room is dynamic and with your permission and all of that you're interacting with the things going on in the room, highly personalised, highly interactive, a very, very interesting world emerges because of the disappearance of the internet.

Similarly, Apple talks about a more "cinematic", "immersive" and "communicative experience". Facebook introduces the curious concept of "true presence" discussing it in terms of building "immersive new technologies that truly give you a sense of presence, that can teleport you to a new place”. Many of these notions seem to take for granted an unproblematic divide between body and mind. True presence seems to imply that all cognitive faculties will reside in a place other than the physical body. This would seem to imply something much stronger than current practices on Second Life or in first player shooter gaming. The specifics of this transformative approach will be further clarified, in terms of change, as functional metaphors, below.

The structural metaphors discussed in this section constitute simplified accounts of how technology is organized and operates. However, they are also, crucially, concerned with human experiences, which intersect with system metaphors, which we describe below.

\section{Functional metaphors - powerful tools}

Functional metaphors refer to design, behaviour, or management of the computer/computer system. Some examples serve as description: computer as tool, as automat, as oracle, as bureaucrat, as person, as game, medium, means of communications, as expert etc. (Dahlbom and Janlert, 1988). The metaphor answers the question: What can computers or computer systems do, or be? The following functional metaphors were used extensively:

Cloud technologies as

- Powerful tools

- Game changer

- Accessibility and connectivity

- Sharing

- Easy and simple

- Fast and quick

- At scale 
- Robust, stable and flexible

\section{Powerful tool metaphor}

It is not at all surprising to find that the metaphor "powerful tools" in GAFA rhetoric is frequently used and plays out in a variation of functional metaphors. This metaphor suggests the empowerment of people and extending agency with the help of technology. A certain tension between the structural metaphors discussed above and the tool metaphor is notable. For instance, moving into another world or being surrounded by a network/ecosystem of technology would suggest that the user is embedded in an environment.

The frequent repetition of the prefix "powerful” is interesting. It seems to suggest that users themselves become more powerful. Science fiction writer Arthur C Clark famously stated: "Any sufficiently advanced technology is indistinguishable from magic" (Clark, 1973) and there is that kind of allure when expressing metaphors of powerful technology. Indeed, as the various statements involving powerful technology were reviewed, it seemed to be most commonly used to generate great emphasis, seemingly pushing it into the domain of magic. For instance, Amazon, when promoting machine learning, sees technology, which "automatically find patterns in existing data and make[s] confident predictions on new data ... a very, very powerful tool”. Similarly, Apple promotes iPads as "tremendously powerful” and promises that "the App Store gives everyone access to incredibly powerful tools".

The dynamic nature of the tools is often emphasized by terms such as "flexible", "dynamic", "elastic" and "scalable" (more below). At times, the powerful tool metaphor is connected to structural metaphors, i.e. implying that the tools are so dynamic that they could change the world. Furthermore, the "powerful tool" metaphor is used to convey cloud as furthering change and making it therefore vital to "adapt quickly to the cloud". This is, arguably, the most emphatic argument made by the representatives of GAFA: the imperative of a quick transition to cloud-based technologies and practices. Amazon's overarching message is the importance for industries and businesses to "adapt quickly to the cloud" for reasons of competitiveness and effectiveness. While most metaphors are used to paint a rosy picture of the cloud-based future, the "adapt quickly"-rhetoric is often threatening:

It is impossible as a big company in this day and age to continue to be competitive if you can't move fast and if you don't use the cloud it's impossible to move as fast as you're going to need to, especially since all of your competitors are using the cloud. (Am)

This is a central and persuasive dimension: acquiring more customers with stronger commitments ASAP. It is therefore not surprising to find several metaphorical devices, with this purpose in mind.

Another way of promoting technology in terms of powerful tools is to portray it as the solution to existing problems within organisations. Usage of the solution metaphor implicitly involves notions of technology as tool. There are many variations on this theme including Google’s image of the “complete solution”, or Amazon's “seamless solution”. Furthermore, 
Facebook talks about an "extension of our brains", comparing with cars viewed as extensions of legs, thus using an anthropomorphic metaphor as a variation of the tool metaphor.

An interesting tension concerns the simultaneous emphasis on tools and "smartness", or "intelligence". As long as the tools are seen as bereft of any agency of their own they can, in some sense, be seen as akin to a hammer. However, how do tools extend human agency when they own an intelligence of their own? Google markets "smart technology" as devices that "talk to each other", while Facebook promotes "intelligent machines/systems" with "natural interfaces", creating "computer systems that understand context in information". Furthermore, all companies are working on artificial intelligence, making their technology "smart", or “intelligent”. Apple describes iOS 9s functionality in terms of intelligence:

You see how we have been able to bring intelligence throughout the experience in iOS 9, but we do it in a way that does not compromise your privacy.

Here the argument is that even if the system is "intelligent", users should not worry about privacy. Nonetheless, it is one of those statements that makes the listener think: should I worry about smart technology and privacy? These intelligent functional properties will not take over. The user will still be in control. However, the articulation of this kind of peaceful coexistence between human and machine-based intelligences is a difficult issue, and rarely pursued in the material.

\section{Game changer metaphor}

Amazon and Apple both zoom in on the "game changer" metaphor. Apple states they have "changed the way in which the world relates to technology" and that they are "creating a better future". They also use this metaphor in connection to the iPhone, which "can be used to battle disease....a game changer... [which] puts people at the center of research". Furthermore Apple claims "iPhone has changed the world". A variation of the game changer metaphor is "the new normal" or "the default".

Functional metaphors, such as "fast" and "at scale", are used in conjunction, arguing cloud as the best operational option, thus prohibiting the mere thought of alternative possible choices. It also bears connotations to simplicity, since you are relieved from repeatedly ticking alternatives.

\section{Accessibility and connectivity}

“Accessibility” includes a large variety of different types of access; for instance access to:

- Internet: "an internet that includes everyone, that's accessible to everyone” (F);

- Computing: "access to computing in several contexts throughout their day-to-day lives, including in their living room” (G);

- A variety of different services/platform/infrastructure: "customers want to access the whole enchilada” (Am);

- IT services and devices: "the App Store gives everyone access to incredibly powerful tools” (Ap); 
- Information: "making the world's information accessible and useful for people everywhere has been at the heart of what Google does" (G);

- Entertainment: "accessing TV shows, movies, music, games and more” (G);

- Photos: "universally accessible [photos]" (Ap);

- Your home: "we're allowing you to access your home remotely and securely via icloud” (Ap).

"Accessibility" and "connectivity" are often intertwined within the frame of functional metaphors. In Google's rhetoric, the term "accessibility" is in line with their objective to give universal access to "the world's information". ${ }^{[1]}$ Seemingly, for Google, access to internet is identical with "connectivity" + "size" + "speed". In Amazon’s rhetoric their web service, AWS Cloud, supplies "direct connect", implying problems of "indirect connect" with conventional internet. This appears a bit surprising, since access appears as more indirect as the cloud provider serves as mediator between user and resources.

Facebook pursues the most emphatic use of "connectivity" in the material, also visible in their mission statement. ${ }^{[2]}$ Facebook's aim is to connect everyone. As with Google, Facebook links connectivity with accessibility. Furthermore, the concept of inclusion is heavily emphasized:

... an internet that includes everyone, that's accessible to everyone... we need voices, technologies, entrepreneurs of all types to reflect the diversity that is the world, so that the voices can be heard and I think we can create a more connected, safer world. (F)

A devastating critique against this kind of rosy-eyed worldview was delivered by Pariser (2011) through the concept "filter bubble". The argument was that Facebook algorithms served to disconnect people from conflicting viewpoints, providing a newsfeed as echo chamber. Facebook metaphors on "connecting the world" and "create a more open and connected future" builds on notions of technological determinism, i.e. more connective technology leads to a more open society. The implication is that societies are endlessly mouldable, adapting to powerful new technology with little or no friction and with purely favourable results. There are many examples of this kind of technological determinism in the Facebook-material. Facebook's VR specialist predicts that

Connectivity will be in everything - everything from your home, to your bicycle and maybe even your pants. These are all going to be connected. This is the world we're going to live in. And I know this is inevitable cause I'm seeing it happen already. (F)

In all fairness, there are Facebook statements admitting technology can lead to problems. However, such difficulties are swiftly brushed aside claiming that "connectivity" and "internet access" creates job opportunities:

If we can extend [internet access] to more people... we increase economic opportunity/job creation. Technology is both a destroyer and a creator of jobs, but it really brings economic opportunity. (F) 
Facebook also states "technology creates jobs in the non-tech world". The use of "non-tech world" is curious, as a central Facebook argument relates to all-inclusive connectivity. As a consequence, a traditional distinction between the IT sector and others would seem to be renegotiated. However, numerous experts predict that IT driven automation is likely to remove substantial amounts of traditional jobs from the employment market. Some predict that almost half of existing jobs are likely to disappear within the next two decades due to automation (Frey and Osborne, 2013).

Facebook signals that they want to make Messenger a place where it becomes easy to "communicate with the businesses you care about in addition to the people you care about". This statement suggests an interesting symmetry in relationships with loved ones and brands. It disguises a structure in which businesses are able to monitor behaviours as well as the social networks of their customers. There is an image of innocence in the way Facebook announces that everything in the world will be all right if only people can connect with each other. Facebook, more clearly than the other organisations studied, disguises the business model with this kind of talk about wanting to make the world a better place: "those moments where we're bringing people together is what we're trying to do at Facebook. It's the core of our mission” (F). This kind of rhetoric ignores the presence of deeply rooted power structures in society as well as disguising the implicit role of Facebook in maintaining digital divides.

\section{Sharing}

Van Dijck (2013) criticized the broad usage of the concept "sharing" in the rhetorical statements of vendors. While users are commonly led to believe that sharing concerns networking between interlinked users, it has also come to include the packaging of usergenerated content "shared with trusted third parties". In addition, through privacy settings on social network sites, such as Facebook, users are led to believe that they can customize the level of sharing. However, it is not possible to control how a cloud corporation such as Facebook disseminates user-generated content among paying customers. In the material, Facebook tends to associate sharing with empowerment.

Both Google and Apple market their photo service with the term "sharing". By being connected users can "share photos...forever" (Ap). Google argues that their photo service "makes it easy to share and save what matters", sharing should be simple and reliable. The business model of corporations such as Google is based on tracking behaviours rather than appropriating user-generated content such as photos (Gehl, 2014). Therefore, it makes sense to present cloud technology as a place for sharing, rather than storage. The metadata connected to photos themselves are of limited interest, it is the metadata concerning what people do with their photos that feeds the business model.

\section{Easy and simple}

Apps, devices and their functions are often characterized as either easy or simple. These metaphors suggest intuitive user interface, demanding little or no information literacy. Sometimes, seemingly for emphasis, both concepts are used: "Simplifies, makes easy and simple” (G). This metaphor is used repeatedly, persuading and promising that cloud 
technologies are attractive to everyone, not exclusively tech-people. At other times, these concepts are used to signal a sense of effortlessness, as if the interface supplies a shortcut between brain and device:

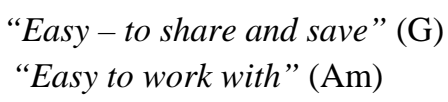

Yet another way of utilizing these seductive concepts is to refer to the user experience as more simple, rich or fun: "[Apple TV] provides a new user experience that's fun and easy to use” (Ap).

Usage of these metaphors can also be tied to the business model of behavioural tracking and the concept of "frictionless sharing" suggested by Mark Zuckerberg in 2011 (Morozov, 2012). The basic notion is that sharing should be as easy as possible, preferably as a default setting. Internet behaviour should be shared automatically. Such a technological development is of course good news for both GAFA and data brokers.

\section{Fast and quick}

Even more prevalent than easy/simple are the metaphors of "fast" or "quick". Once again, this promotes a business model where people are enticed to maximize sharing for the benefit of behavioural tracking. However, representatives of GAFA know that speed is seductive and that users are easily sold on fast technology. Therefore, speed can be described as a thing of beauty: "[Google Photo] is fast, intuitive and beautiful".

Indeed, Google frequently describes their devices or services as “beautiful” technology: “...to create beautiful and useful devices and the result is choice”. Descriptions of new technology as "fast" and "beautiful" can be seen as parallel to the selling of a new sleek sports car: "use the cloud to move faster than ever" (Am). However, it is equally important to emphasize that increased speed does not come at the price of other important functionality:

We're committed to make our platform really, really stable, move fast with stable infra[structure] operating at scale. Stability is how you move quickly. (F)

\section{At scale}

Just about any positive qualifier is used to describe the greatness and desirability of cloud technology. Size is an obvious target, usually not "big” or "large”, but instead "at scale”, utilized by all companies. This is probably a carefully selected concept which signals that technology need not overwhelm you with its scope. Rather, it is scaled to the needs of the individual customer and can be scaled up for growth. This metaphor is useful for the various types of technology involved, such as mobile devices - "Android is working at scale” (G) and infrastructure - "Move fast with stable infra[structure] operating at scale" (F). The concept can also be used to paint a grand vision: 


\section{Robust, stable and flexible}

Terms like "stable", "robust" or "reliable" are often used in GAFA rhetoric. The usage is similar to metaphors relating to "fast", discussed above. This is one of the strongest selling points of cloud technology, enticing organisations away from what can be seen as the fragility of individual hard disks. The downside of storage and processing on the cloud is its vulnerability to hacking and the theft of corporate intellectual properties. Emphasizing robustness is a way of promoting similar issues while steering away from data security aspects. However, there is a sense of pride in the robustness of the technology:

“... running reliable, scalable infrastructure services deep in the stack and reliable, scalable cost effective datacenters" (Am)

The functional metaphors are, at least in some cases, closely related to the final category, system metaphors.

\section{System metaphors}

The system metaphor depicts the computer and computer's role as the connection between people and computers. Examples of this role are the computer as resource, as producers, as deliberator or component in an automatic system, also, computer use as craft or game (Dahlbom and Janlert, 1988). Once it is established that the technology can be seen as a powerful (easy, fast, scalable and stable) tool, the next question concerns what can be done with such a resource. System metaphors show the purpose of the computer and answer the question: What can one do with computers or computer systems? The following system metaphors were identified:

Cloud technologies as

- Enabling control

- Empowering

- Enabling choice

- Limitless possibilities

\section{Enabling control - "be in control"}

All GAFA companies address the control issue, but in different ways. Facebook states they have a "people first"-approach:

by making them [users] sure that we keep everyone safe, by giving people more control over their experiences. Because, when people feel good about their privacy and their security, that's when they're open to try all these new experiences.

This argument is thereafter extended to Facebook login, which is said "to give people complete control over the information they share with apps". This is a dubious argument as such login practices ultimately serve to give Facebook control over a wealth of user-generated content beyond the boundaries of their own platform. 
Similarly, Apple talks about control, both in connection to the use of their iOS 9 - "You're in control" (Ap) - and in connection to remote control of devices - "we're allowing you to access your home remotely and securely via iCloud, so no matter where you are you can control your home kit devices” (Ap). These metaphors are, seemingly, constructed to counter experiences of losing control in the face of a dramatic technological shift. Arguably, it is unavoidable that visions, relating to ever more powerful tools, are by some users met with enthusiasm and by some with desperation. Naturally, cloud technologies will also be implemented quite unevenly in society. This suggests that some actors will be able to exert more control over technology than others. The many statements concerning "you are in control” do not connect to issues about control as societal power. Instead, the concept of power is used as an expression of personal empowerment, which is focused next.

\section{Empowering - "everyone can"}

Amazon provides users with the opportunity of designing their own platform, which, they say, enables users to customize their own websites: "users feel that the website is their own, which is empowering”. Similarly, Facebook's market rhetoric is directed toward empowering users: "Everyone has voice ... everyone can post, everyone can share, and that gives voice to people that historically have not had it”. This seems to be an implicit assumption in the Facebook argument that more technology equals more happiness and empowerment: "As the internet spreads and as phones spread people are getting the power to share and express themselves [...] and building better businesses”. All in all, Facebook portrays itself as a Robin Hood-like equalizer, giving people power they otherwise would not have: "This is how we give people the power to share and to make the world more open and connected”. In a similar vein, Apple wants "to make the best products in the world that empower people that enrich their lives".

\section{Enabling choice - "the way you like it"}

The customization of cloud technology appears to be a major selling point. Google states that they "want to provide Android for users the way they like it, so that it works for them". Similarly, Amazon suggests that "cloud computing is a broad set of platforms and services, which you can stitch together in any way you really want to". These technology providers seem at times to be at a loss to describe the particulars of what they are promoting as it can be transformed to anything the user desires. This is articulated most clearly by Apple in their presentation of the iPad, which, it is claimed, can "virtually transform to anything you want it to be” and a multi touch keyboard that "can transform to anything you want".

Connected to customization there is also frequent usage of the metaphor of "choice", used by both Google and Amazon. Google claims to afford choice, for instance through applications such as Android Pay, which is: “...focused on simplicity, security and choice”, or through devices such as Android Wear: "to create beautiful and useful devices and the result is choice".

In a Facebook driven world, there is, seemingly, no room for unpredictable input into the "great life". Users already know what they want and can customize life accordingly, thanks to sophisticated control technology: 
We want you to spend every minute of your day and have control over what you look at, what you see and what you interact with. A great life is where you can spend the time on the things you want, and most importantly, with the people you want. And by building systems that understand the context of the world, understand what it is you want. We can help you there. We can build these systems that make sure all of us spend time on the things we care about. That's the promise of applying AI to something like this (F)

The persuasive rhetoric of choice creates an image of providing greater scope for developing and using technology on one's own premises.

There's really so many possibilities to use these platforms and these tools to create unbelievable apps that will impact business and healthcare and education and really everything in our lives. There's seemingly no limit to what you can do (Ap)

In this statement, the scope for choice is completely limitless. In sum, the rhetoric of choice creates an image of technology as malleable. The user is the potter and technology is the clay. Nonetheless, the scenario depicted here can also be seen as restricting choice. In life situations not mediated by technology, we constantly are placed in surprising situations. We learn and develop new skills by making choices in such situations. By moving into technological environments where our paths in life are either preselected by ourselves or filtered automatically by machines, we are herded away from chance encounters, serendipity and challenges. The great life, described by Facebook, becomes one where we spend time on the things we may have had an earlier experience of wanting. However, human beings need to grow as we move through our lifespan of childhood, adolescence and adulthood.

\section{Discussion}

We have discussed an abundance of metaphors used to promote cloud technology. These can be seen as being put to work in the stitching together of simplified accounts that make certain aspects visible, while hiding others. The overarching aim of GAFA seems to be disconnected from business models and instead concerned with the improvement of people's lives, making the world a better place. However, this is, of course, a strategic choice of narrative as the material consists of spokespeople from powerful multinational corporations and not representatives of public service institutions. With some exceptions, metaphor use is surprisingly similar, even though the rhetoric can have slightly different focus or emphasis, i.e. Facebook claims a "people-first"-approach, while Amazon, instead, promotes "cloudfirst”.

The most varied metaphor use seems to relate to empowerment. Empowerment has positive associations and breathes self-esteem and liberty. It tends to hide any doubt of freedom of action, energy and drive to accomplish greatness. Furthermore, empowerment goes hand in hand with the promise of transformation. Over and over again metaphors connected to transformation are used as a persuasive device in connection to most of the metaphors identified. It is taken for granted that change is nothing but positive. 
As expected, some themes are not addressed, for instance, technology/internet dependency and organisational aspects related to new ways of carrying out work and managing information. Research shows that new sociotechnical systems have implications for organisations and involve great complexity (Feltovich et al., 2004). They are "inhabited by multiple viewpoints, multiple value systems, multiple ways of operating, multiple assessments of responsibility and authority, and the like”. They depend on people's different "backgrounds, experiences, responsibilities, personal agendas, and particular tasks" (Feltovich et al., 2004, p. 92).

Furthermore, complexity is avoided while simplicity and predictability are asserted. A certain extent of predictability is important for both humans, to live their lives, and for companies in an uncertain competitive environment. When predictability and competitiveness become the only overarching aim, thus seemingly exterminating serendipity in everyday life, there is a risk that the technology introduces substantial problems within both organisations and personal life.

Undoubtedly, the implementation and use of new IT is much more complex than GAFA rhetoric implies. However, as the material studied is focused on marketing, the emphasis on positive qualities is, of course, to be expected. Through their metaphors, GAFA holds forward a promising utopia of new technology, in which people and companies are in control, become empowered, and everyday life activities are transformed. To accomplish this and to keep the competitors at arm's length, better infrastructures and platforms together with more services and devices need to be connected in an ever-larger network. This will be accomplished with the help of partner system developers and users. The convergence within GAFA, with similar cloud technology/services and metaphors used to explain this technology, makes it relevant to talk about GAFA's filter bubble (compare Pariser, 2011), as explained by their cultural origin - Silicon Valley (Keen, 2012).

It is a problematic situation when the cultural, economic and technological elite, geographically situated in Silicon Valley, can produce/distribute technological hardware, software and narratives to, and for, the rest of the world. This involves new forms of power acting from a distance (Latour, 1989). Arguably, the corporations of GAFA are in the business of developing not only new forms of technologies for exerting power from a distance, but also narratives, involving people from all over the world being powered from a distance. Cloud technology affords dimensions that legacy IT systems have not had, such as the ability to connect huge amounts of data from multiple sources, to aggregate and process this data, and furthermore, to do this in real time. On the whole, GAFA seems to be converging towards the same type of business model. These corporations are not only gaining wealth through personalized marketing and artificial intelligence by access to big data and algorithms, which are based on users' behaviour on the web (Fuchs, 2012), but also excessive political influence by acting from a distance through their "connective media” (van Dijck, 2013) of "vertically integrated chains” (Couldry \& van Dijck, 2015). 
Access is no longer limited, but open to cloud vendors and their third parties. People are commonly not aware of, or downplay, these back end properties of cloud technology (Lindh \& Nolin, 2016). The power of the metaphors is in the hands of those who use them. Therefore, the metaphors in GAFA rhetoric hide these negative effects of cloud technology. The technology of YouTube, itself a GAFA-owned cloud-based application, megaphones the metaphors.

That said, metaphors tend to have lifecycles. Some metaphors will persist and others may fade. Interestingly, Lindh (2016) could trace the utility metaphor, continuously used to describe computing and IT, back to the late 50s. In the investigation at hand, this metaphor is no longer used as a persuasive device for the promulgation of IT. One could argue that the utility metaphor is now taken for granted and institutionalized. Persuasive arguments have transformed into more forceful talk, stressing the power of this utility to change lives and give people immanent experiences. In addition, the utility-metaphor signals a certain distance between user and technology. We use utilities such as water, electricity and computing in order to carry out our everyday activities. The metaphors investigated in the current article allows for a much closer interaction between humans and their devices. The world in which we live in is seen as intrinsically technological and we live through our devices. This is most clearly articulated in the life-metaphors. It should be emphasized that technology as life involves use of this source domain in a way that has been around for a while. Already in 2008, Charlene Li, a prolific social media expert at Forrester Research, stated that: "I believe that in the future, social networks will be like air... without that social context in our connected lives, we won't really feel like we are truly living and alive, just as without sufficient air, we won't really be able to breathe deeply”.

In this article, we have been concerned with a distinction between cloud technology and the narratives that are used to describe and promote it. However, as we move forward into the kind of scenarios suggested in our material, we see an increasing convergence of the narrative with the technology itself. Living and breathing through technology could also lead to difficulties in understanding structural transformations in society as well as recognition of one's self as separate from technology.

\section{Conclusion}

Building on 13 presentations held by top representatives of the corporate leaders of GAFA, numerous metaphors were utilized in order to describe and promote future practices relating to cloud technology. Utilizing the conceptual metaphor theory by Lakoff and Johnson (2003), together with the employment of a typology developed by Dahlbom and Janlert (1988), various persuasive devices were identified and categorised according to structural, functional or system metaphors. The main thrust of the material was to communicate a utopian image of revolutionizing technology with purely positive dimensions. In some sense, this result is not surprising, given the investigational scope of gathering various forms of promotional material. Nonetheless, it is important to scrutinize these metaphors, as they are likely to be frequently used within a multitude of organisations in order to create legitimacy for this technology. 
Although GAFA visions can be communicated with optimism, there are explicit or implicit problematic aspects linked to them. Automation can liberate, but also undercut human agency. Control and empowerment can work both ways and users can be led into following the advice of their highly informed smart phones, rather than their own heads. In the material, "revolution" and "transformation" were used in order to describe how people move from an old world to a new. This was seen as unproblematic, involving purely fruitful outcomes. However, history teaches us that revolutions tend to be bloody affairs, taking a huge toll.

Even though the revolutions talked about may differ greatly from the French Revolution, the scope for change appears to be more dramatic. The current article is a contribution to the discussion of talk about technology-rich futures. It is also a contribution to the discussion of the processes of legitimization of new technologies in society, in organisations and for individuals. We argue that this is an area in increasing need of reflection and intervention from policymakers, organisational leaders, social scientists and IT promulgators.

\section{References}

- Agrawal, D., Das, S. and El Abbadi, A. (2011), "Big data and cloud computing: current state and future opportunities", in Proceedings of the 14th International Conference on Extending Database Technology, Uppsala, Sweden, March 22-24, 2011, ACM, pp. 530-533.

- Barnatt, C. (2010), A Brief Guide to Cloud Computing, Robinson, London.

- Bartis, E. and Mitev, N. (2008), “A multiple narrative approach to information systems failure: a successful system that failed”, European Journal of Information Systems, Vol. 17, No. 2, pp. 112-124.

- Buyya, R., Yeo, C.S., Venugopal, S., Broberg, J. and Brandic, I. (2009), "Cloud computing and emerging IT platforms: vision, hype, and reality for delivering computing as the 5th utility”. Future Generation Computer Systems, Vol. 25, No. 6, pp. 599-616.

- Callon, M. (1986), "Some elements of a sociology of translation: domestication of the scallops and the fishermen”, in Law, J. (Ed.), Power, Action and Belief: A New Sociology of Knowledge, Routledge \& Kegan Paul, London, pp. 197-225.

- Carr, N. (2014), The Glass Cage: Automation and Us, W. W. Norton \& Company, Inc, London.

- Carr, N. (2008), The Big Switch: Rewiring the World, from Edison to Google, 1st ed., W. W. Norton, New York, London.

- Case, A. (2015), Calm Technology: Designing for Billions of Devices and the Internet of Things. O'Reilly Media, Inc.

- Clarke, A.C. (1973), Profiles of the Future, Harper \& Row, New York.

- Dahlbom, B. and Janlert L-E. (1988), En artificiell värld: forskningsläge och forskningsbehov, Arbetsmiljöfonden och Styrelsen för teknisk utveckling, MDArapport, Stockholm. 
- Feltovich, P.J., Hoffman, R.R., Woods, D. and Roesler, A. (2004), “Keeping it too simple: how the reductive tendency affects cognitive engineering”, Intelligent Systems, IEEE Computer Society, Vol. 19, No. 3, pp. 90-94.

- Frey, C.B. and Osborne, M.A. (2013), The Future of Employment: How Susceptible are Jobs to Computerisation, Oxford Martin School, Oxford, available at: https://www.google.se/url?sa=t\&rct=j\&q=\&esrc=s\&source=web\&cd=1\&ved=0ahUK EwjtsN_5_vHKAhXKE5oKHWBXDSAQFggcMAA\&url=http\%3A\%2F\%2Fwww.o xfordmartin.ox.ac.uk\%2Fdownloads\%2Facademic\%2FThe_Future_of_Employment.p df\&usg=AFQjCNFujcxMopCcadhq7bdkRjZoy0qCYg\&cad=rja (accessed 24 August 2016)

- Fuchs, C. (2012), “Google capitalism”, tripleC: Communication, Capitalism \& Critique. Open Access Journal for a Global Sustainable Information Society, Vol. 10, No. 1, pp. 42-48.

- Gehl, R.W. (2014), Reverse Engineering Social Media: Software, Culture, and Political Economy in New Media Capitalism, Temple University Press, Philadelphia.

- Hamilton, A. (2000), "Metaphor in theory and practice: the influence of metaphors on expectations”, ACM Journal of Computer Documentation, Vol. 24, No. 4, pp. 237253.

- Hirschheim, R.A. and Newman, M. (1991), "Symbolism and information systems development: myth, metaphor and magic”, Information Systems Research, Vol. 2, No. 1, pp. 29-62.

- Hwang, K., Dongarra, J. and Fox, G.C. (2013), Distributed and Cloud Computing: From Parallel Processing to the Internet of Things, Morgan Kaufmann.

- Johansson, M. (1997), Smart, Fast and Beautiful: on Rhetoric of Technology and Computing Discourse in Sweden 1955-1995, PhD thesis, University of Linköping, Linköping.

- Keen, A. (2012), Digital Vertigo: How Today's Online Social Revolution is Dividing, Diminishing, and Disorienting Us, Constable, London.

- Kling, R. (1996), "The centrality of organizations in the computerization of society”, in Kling, R. (Ed.), Computerization and Controversy: Value Conflicts and Social Choices, $2^{\text {nd }}$ ed., Academic Press San Diego, pp. 108-132.

- Lakoff, G. (1993). The Contemporary Theory of Metaphor. In A. Ortony (Ed.), Metaphor and thought (pp. 202-251), $2^{\text {nd }}$ ed., Cambridge University Press, Cambridge.

- Lakoff, G. and Johnson, M. (2003), Metaphors We Live By, University of Chicago Press, Chicago.

- Latour, B. (1989). The Politics of Explanation: An Alternative. In S. Woolgar (Ed.), Knowledge and Reflexivity: New Frontiers in the Sociology of Knowledge, Sage Publications, London.

- Li, C. (2008), “The future of social networks: Social networks will be like air”, Social Media Today, 6 March, available at: http://www.socialmediatoday.com/content/futuresocial-networks-social-networks-will-be-air (accessed 24 August 2016) 
- Lindh, M. (2016), “As a utility: metaphors of information technologies”, HumanIT, Vol. 13, No. 2, pp. 47-80.

- Lindh, M. and Nolin, J. (2016). Information We Collect: Surveillance and Privacy in the Implementation of Google Apps for Education. European Educational Research Journal, Vol. 6, pp. 1-20.

- $\quad$ Lynn Kaarst-Brown, M. and Robey, D. (1999), "More on myth, magic and metaphor: cultural insights into the management of information technology in organizations”, Information Technology \& People, Vol. 12, No. 2, pp. 192-218.

- Marshall, S. (2010), "Change, technology and higher education: are universities capable of organisational change?”, Research in Learning Technology, Vol. 18, No. 3, pp. 179-192.

- Morozov, E. (2012), The Net Delusion: How not to Liberate the World, Penguin, London.

- Norman, D.A. (1998), The Invisible Computer: Why Good Products Fail, the Personal Computer Is So Complex, and Information Appliances Are the Solution, The MIT Press, Cambridge, Massachusetts.

- Olson, N. (2015), "Semantic web, ubiquitous computing, or internet of things? A macro-analysis of scholarly publications”, Journal of Documentation, Vol. 71, No. 5, pp. 884- 916.

- Orlikowski, W.J. (1992), “The duality of technology: rethinking the concept of technology in organizations”, Organization Science, Vol. 3, No. 3, pp. 398-427.

- Pariser, E. (2012), The Filter Bubble: What the Internet is Hiding From You, Penguin Books, London.

- Sturken, M., Thomas, D. and Ball-Rokeach, S.J. (2004), Technological Visions: The Hopes and Fears that Shape New Technologies, Temple University Press, Philadelphia.

- van Dijck, J. (2013), The Culture of Connectivity: A Critical History of Social Media, Oxford University Press, Oxford.

- Wang, H., Yu, Y., Zhu, P. and Yuan, Q. (2011), “Cloud computing based on internet of things", in Second International Conference on Mechanic Automation and Control Engineering, Hohhot, China, July 15-17, 2011, IEEE, pp. 1106-1108.

- Willcocks, L., Venters, W. and Whitley, E.A. (2014), Moving to the Cloud Corporation: How to Face the Challenges and Harness the Potential of Cloud Computing, Palgrave, Macmillan, New York.

- Winner, L. (1986), The Whale and the Reactor, Univ. of Chicago Press, Chicago.

- Xu, X. (2012), "From cloud computing to cloud manufacturing", Robotics and Computer-Integrated Manufacturing, Vol. 28, No. 1, pp. 75-86.

[1] About Google, available at: https://www.google.se/intl/en/about/ (accessed 24 August 2016)

[2] "Facebook's mission is to give people the power to share and make the world more open and connected", available at: https://www.facebook.com/facebook/info?tab=page_info (accessed 24 August 2016) 